\title{
Oxidation-Induced Detachment of Ruthenoarene Units and Oxygen Insertion in Bis-Pd(II) Hexaphyrin $\pi$-Ruthenium Complexes
}

\author{
Akito Nakai, Takayuki Tanaka *(D) and Atsuhiro Osuka* \\ Department of Chemistry, Graduate School of Science, Kyoto University, Kyoto 606-8502, Japan; \\ nakai@shuyu.kuchem.kyoto-u.ac.jp \\ * Correspondence: taka@kuchem.kyoto-u.ac.jp (T.T.); osuka@kuchem.kyoto-u.ac.jp (A.O.); \\ Tel.: +81-(0)75-753-4007 (T.T.)
}

Academic Editors: Derek J. McPhee, M. Salomé Rodríguez-Morgade and Soji Shimizu Received: 27 May 2020; Accepted: 12 June 2020; Published: 15 June 2020

\begin{abstract}
Two types of new bis-Pd(II) hexaphyrin $\pi$-ruthenium complexes are reported. A double-decker bis-Pd(II) hexaphyrin $\pi$-ruthenium complex 4 was obtained by oxidation-induced detachment of a ruthenoarene unit from the triple-decker complex 3 and oxygen-inserted triple-decker bis-Pd(II) hexaphyrin $\pi$-ruthenium complex $\mathbf{6}$ was obtained upon treatment of bis-Pd(II) [26]hexaphyrin 5 with $\left[\mathrm{RuCl}_{2} \text { ( } p \text {-cymene) }\right]_{2}$ under aerobic conditions. Although $\pi$-metal complexation of porphyrinoids often results in decreased global aromaticity due to the enhancement of local $6 \pi$ aromatic segments, distinct aromatic characters were indicated for 4 and 6 by ${ }^{1} \mathrm{H}-\mathrm{NMR}$ spectral and theoretical calculations. These results are accounted for in terms of possible resonance contributors of hexaphyrin di- and tetraanion ligands. Thus, $\pi$-metal coordination has been shown to be effective for modulation of the overall aromaticity.
\end{abstract}

Keywords: expanded porphyrin; $\pi$-complex; ruthenium complex; aromaticity

\section{Introduction}

Expanded porphyrins which consist of more than four pyrrole units and methine carbons, have been attracting continuous attention due to their intriguing optical and electrochemical properties, structural diversities, and rich coordination abilities [1-7]. The structural and electronic characteristics of expanded porphyrins are usually quite flexible, which has been used for versatile and efficient modulation of aromaticity by redox reactions and structural modifications [5-7]. Recently, we report a new $\pi$-metal coordination type, wherein a ( $p$-cymene) $\mathrm{Ru} \mathrm{u}^{\mathrm{II}}$ fragment is $\eta^{5}$-coordinated at the side pyrrole of bis-Au(III) [28]hexaphyrin, forming double-decker $\pi$-ruthenium complexes 1 and 2 (Figure 1) [8]. On the other hand, triple-decker $\pi$-ruthenium complex of bis-Pd(II) [26] hexaphyrin 3 possesses two ( $p$-cymene) $\mathrm{Ru} \mathrm{u}^{\mathrm{II}}$ fragments sitting on the two $\mathrm{Pd}^{\mathrm{II}}$ metal centers and the inner pyrrolic $\beta$-carbon atoms in a $\eta^{6}$-coordinated manner on both sides of the hexaphyrin. In the literature, $\pi$-metal complexes of porphyrinoids have been limited to those based on porphyrin, porphycene, subphthalocyanine, and subporphyrazine scaffolds [9-16], and no examples had been reported for expanded porphyrin $\pi$-metal complexes before our report [8]. Interestingly, complexes $\mathbf{1}$ and $\mathbf{2}$ showed attenuated macrocyclic paratropic ring currents, probably due to the coordination-induced attenuation of the global conjugation circuit, while complex 3 showed distinct $26 \pi$ aromaticity. This difference suggested

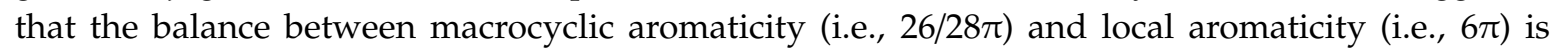
important and can be modulated by metal $\pi$-complexation [17]. This finding drove us to explore new $\pi$-ruthenium complexes of hexaphyrin. Here we report double-decker bis-Pd(II)[26]hexaphyrin $\pi$-ruthenium complex 4 and oxygen-inserted triple-decker bis-Pd(II) [26]hexaphyrin 6. Both complexes show a distinct diatropic ring current. 


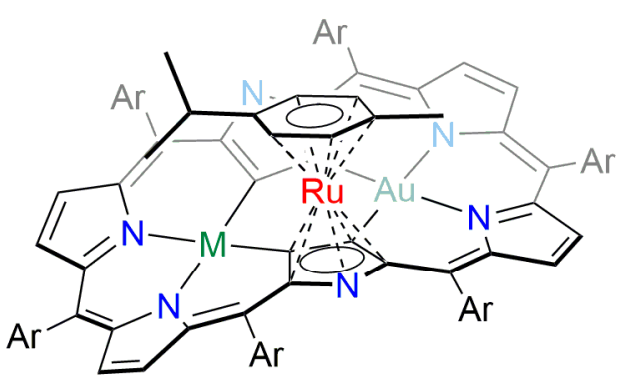

1: $M=A u$

$2: M=3 \mathrm{H}$

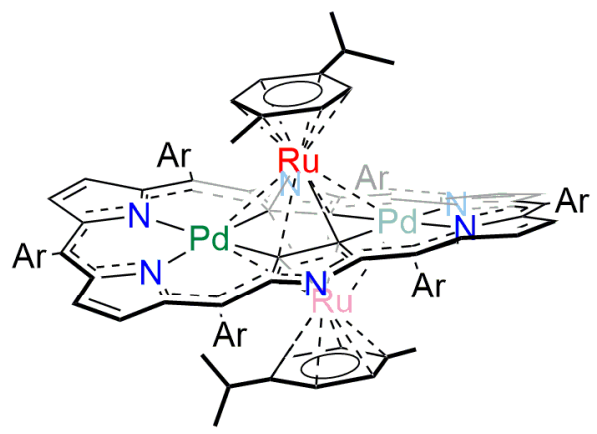

3

Figure 1. Schematic drawing of $\pi$-ruthenium complexes of hexaphyrins. Ar = pentafluorophenyl.

\section{Results and Discussion}

Our investigation started with an attempted oxidation of triple-decker $\pi$-ruthenium complex 3 since 3 has a relatively electron-rich character $\left(E_{\text {ox. } 1}=0.22 \mathrm{~V}\right.$ vs Fc/Fc $\left.{ }^{+}\right)$[8]. Therefore, oxidative titration of 3 with tris(4-bromophenyl)ammoniumyl hexachloroantimonate (TBAH) was examined. Upon addition of TBAH, 3 showed clear absorption spectral changes with isosbestic points at 426 , 620,846 , and $978 \mathrm{~nm}$ to a spectrum with absorption maxima at 461, 624, and $799 \mathrm{~nm}$ (Figure S4). These spectral changes suggested ring-centered oxidation rather than metal-centered oxidation [18]. Thus we attempted to isolate the oxidized species but failed due to the instability of the oxidized species under ambient conditions. Meanwhile, we found that treatment of $\mathbf{3}$ with an excess amount of TBAH afforded a different species, 4 , in $41 \%$ yield as an entity stable under ambient conditions (Scheme 1).

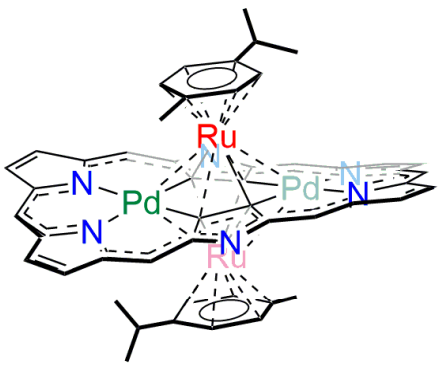

3

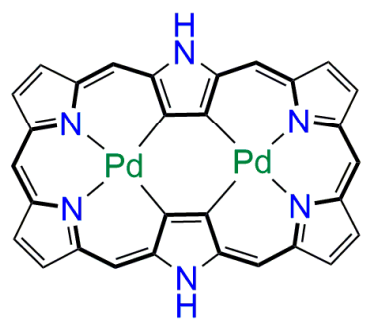

excess TBAH

$\mathrm{CH}_{2} \mathrm{Cl}_{2}, \mathrm{RT}, 10 \mathrm{~min}$.

5 eq. $\left[\mathrm{RuCl}_{2}(p \text {-cymene })\right]_{2}$

10 eq. $\mathrm{NaOAc}$

toluene / DMF, RT, $13 \mathrm{~h}$

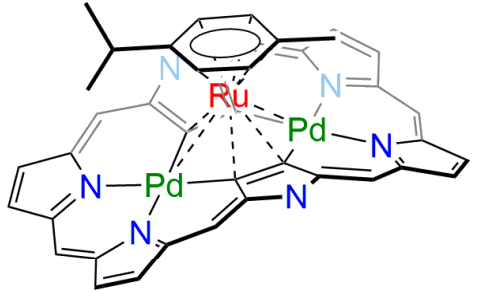

$4(41 \%)$

5

Scheme 1. Synthesis of 4. meso-Pentafluorophenyl groups are omitted for clarity. 
The complex 4 shows its molecular ion peak at $m / z=1901.8531$ (calcd. for $\mathrm{C}_{76} \mathrm{H}_{22} \mathrm{~F}_{30} \mathrm{~N}_{6}{ }^{106} \mathrm{Pd}_{2}{ }^{102} \mathrm{Ru}$ $[\mathrm{M}]^{-}:$1901.8589) by high-resolution atmospheric-pressure-chemical-ionization time-of-flight (HR-APCI-TOF) mass spectrometry, that corresponds to the double-decker complex. Indeed, treatment of [26]hexaphyrin bis-Pd(II) complex 5 [19] with 5 equivalents of $\left[\mathrm{RuCl}_{2} \text { ( } p \text {-cymene) }\right]_{2}$ in the presence of sodium acetate at room temperature gave the same double-decker complex 4 in $71 \%$ yield along with triple-decker complex 3 ( $5 \%$ yield).

The structure of 4 was determined by X-ray crystallographic analysis as shown in Figure 2. The ( $p$-cymene) $\mathrm{Ru}^{\mathrm{II}}$ fragment is located just above the center of the hexaphyrin framework in the same manner as the triple-decker complex 3. The ruthenium ion (Ru1) is strongly coordinated to C2 and C4 as judged by their shorter bond lengths by about $0.1 \AA$ than Ru1-C1 and Ru1-C3 bonds. Accordingly, the coordination of the ruthenium ion to $\mathrm{C} 1, \mathrm{C} 3, \mathrm{Pd} 1$ and $\mathrm{Pd} 2$ would be weaker similar to the case of triple-decker complex 3. Interestingly, 4 takes a columnar stack structure and the interplanar distances between the hexaphyrin plane and p-cymene of another molecule were 3.441 and $3.380 \AA$ (Figure S8).

(a)

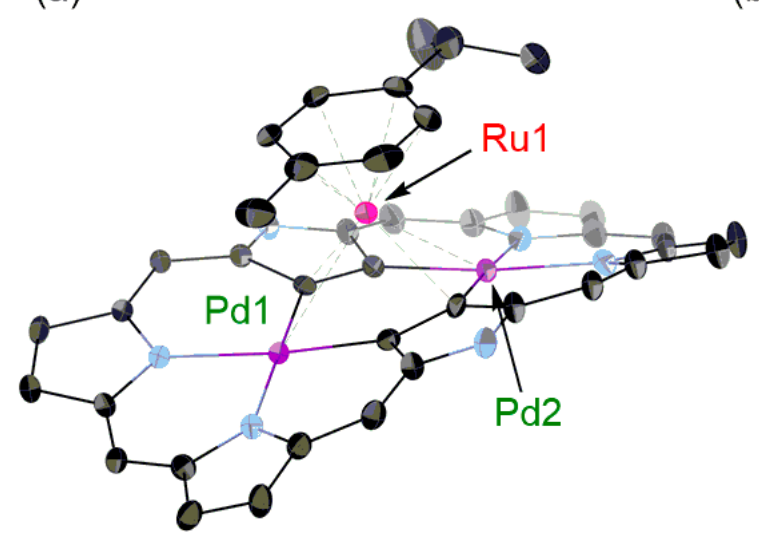

(b)

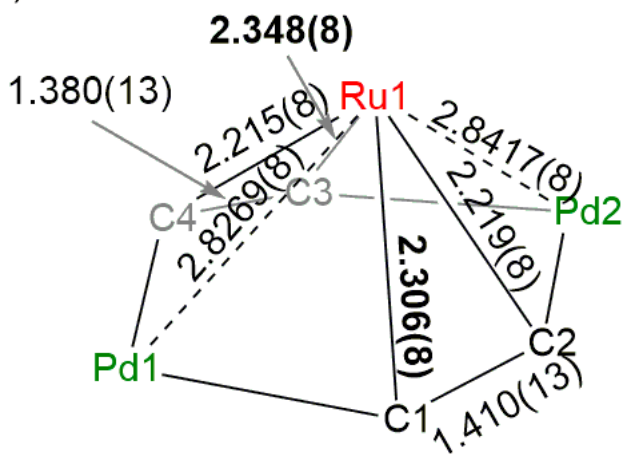

Figure 2. (a) X-Ray crystal structure of 4 . The thermal ellipsoids are $25 \%$ probability. One of two independent molecules is shown. Solvent molecules, pentafluorophenyl groups and hydrogen atoms are omitted for clarity. (b) Detailed bond lengths (unit: $\AA$ ).

The ${ }^{1} \mathrm{H}$-NMR spectrum of 4 showed two doublet signals due to the outer $\beta$-protons at $\delta=9.45$ and $9.24 \mathrm{ppm}$, indicating a distinct diatropic ring current arising from its $26 \pi$ aromaticity (Figure 3 ). These signals were slightly downfield-shifted as compared with those of triple-decker complex 3 and parent hexaphyrin 5, suggesting the aromaticity of 4 was enhanced. This consideration was also supported by more upfield-shifted ${ }^{1} \mathrm{H}$-NMR peaks of the $p$-cymene fragment of 4 compared with those of 3 . This enhanced aromaticity may be accounted for in terms of possible resonance contributors of the hexaphyrin ligands (vide infra). The UV/Vis/NIR absorption spectra of 3, 4 and 5 are shown in Figure 4. In 3, three absorption maxima are observed at 461,650 , and $829 \mathrm{~nm}$, while a large absorption band at $578 \mathrm{~nm}$ and weak Q-like bands at 895 and $1004 \mathrm{~nm}$ are observed in 5. Unlike 3 and 5, the absorption spectrum of 4 shows more complicated bands and a weak absorption tail up to $1800 \mathrm{~nm}$, and is almost insensitive to solvent polarity (Figure S5). 
(a) 5
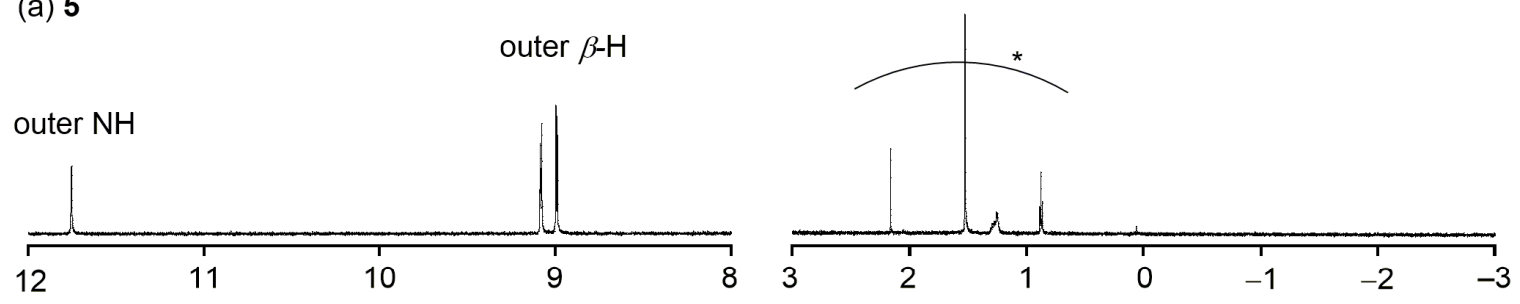

(b) 4
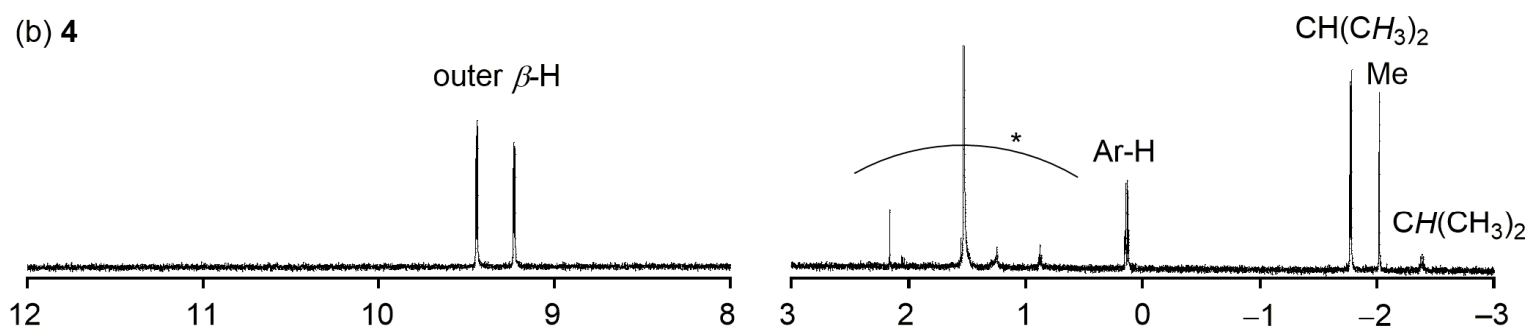

(c) 3

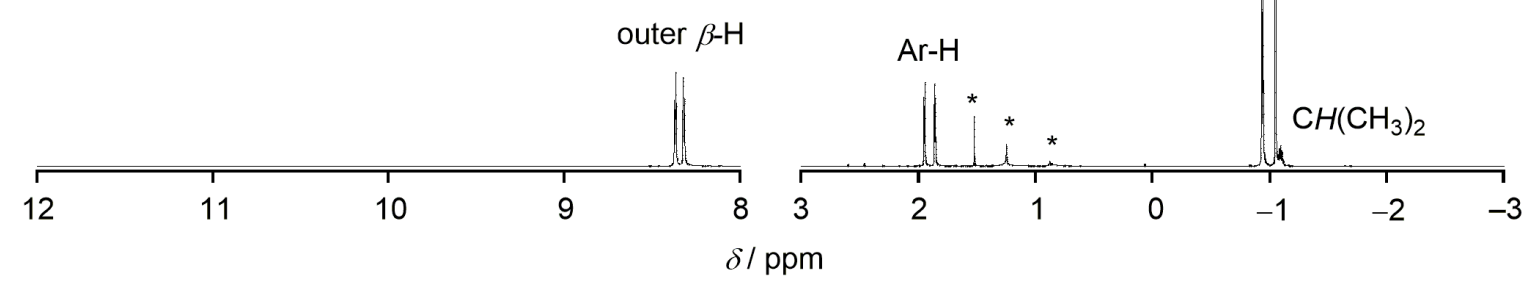

Figure 3. ${ }^{1} \mathrm{H}-\mathrm{NMR}$ spectra of (a) 5, (b) 4 and (c) 3 in $\mathrm{CDCl}_{3}$ at room temperature. Asterisks mean residual solvent and impurity.

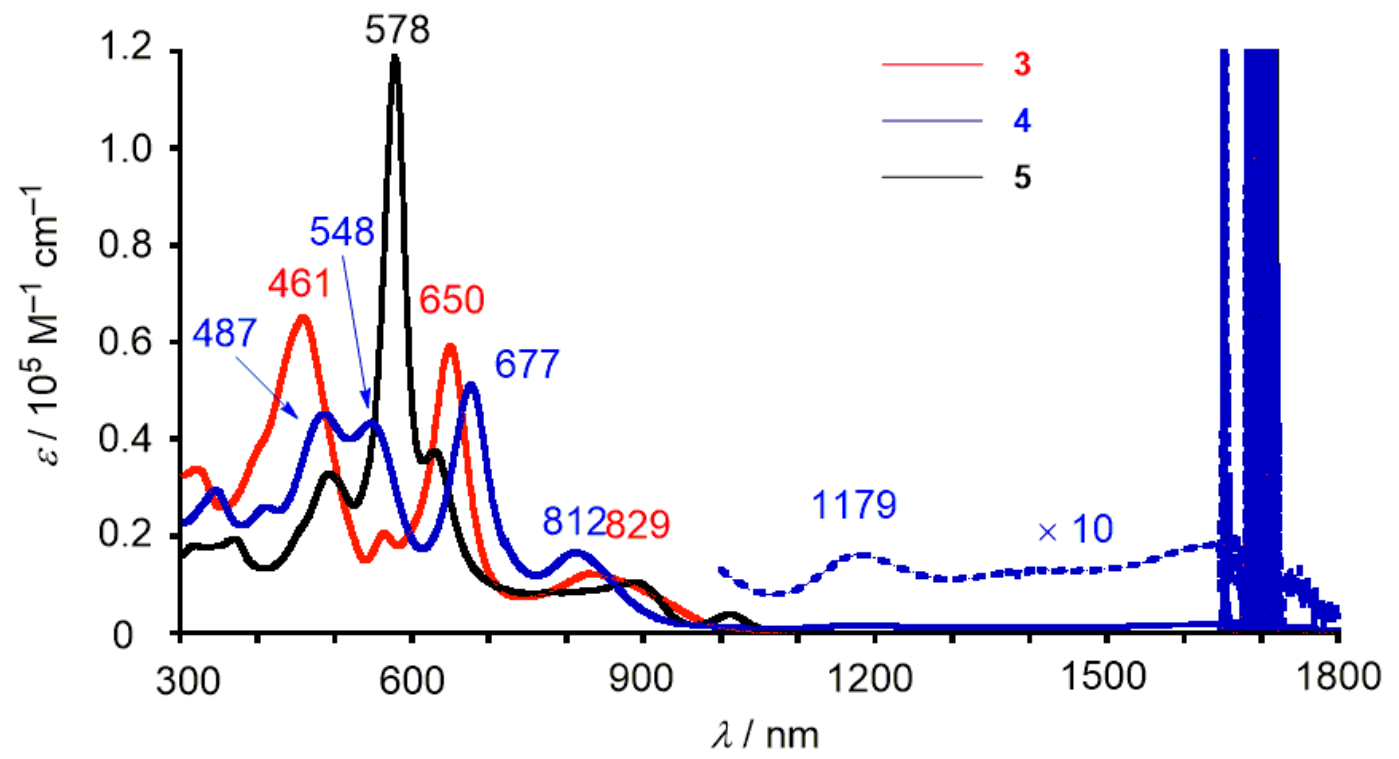

Figure 4. Absorption spectra of 3 (red), 4 (blue) and 5 (black) in $\mathrm{CH}_{2} \mathrm{Cl}_{2}$.

During the optimization of the reaction conditions, we found that a trace amount of oxygen-inserted triple-decker complex 6 was formed upon reaction of 5 with $\left[\mathrm{RuCl}_{2}(p \text {-cymene) }]_{2}\right.$ in air (Scheme 2). The HR-APCI-TOF MS gave the molecular ion peak of 6 at $\mathrm{m} / z=2153.8690$ (calcd. for $\mathrm{C}_{86} \mathrm{H}_{36} \mathrm{~F}_{30} \mathrm{~N}_{6} \mathrm{O}^{106} \mathrm{Pd}_{2}{ }^{102} \mathrm{Ru}_{2},[\mathrm{M}]^{-}:$2153.8682). The yield of 6 was improved up to $35 \%$ when the reaction was run in the presence of an excess amount (ca. 555 eq.) of water. However, the reaction in 
the presence of $\mathrm{H}_{2}{ }^{18} \mathrm{O}$ did not afford the corresponding ${ }^{18} \mathrm{O}$-incorporated product, indicating that the oxygen source might be molecular oxygen. X-Ray crystallographic analysis revealed that the oxygen atom was actually inserted between the $\beta$-carbon (C1) and Ru1 (Figure 5). The Pd1-Ru1, Pd1-Ru2, Pd2-Ru1, and Pd2-Ru2 bond lengths are 2.9548(5), 2.9651(6), 3.1146(6), and 2.8568(5) A, respectively, all being shorter than the sums of the van der Waals radii of $\mathrm{Pd}$ and $\mathrm{Ru}$ [20]. Density functional theory (DFT) calculations [21] also indicated the weak coordinating interactions between the $\mathrm{Ru}$ and $\mathrm{Pd}$ (Table S2). The oxygen atom (O1) is bound to Ru1 (2.120(2) $\mathrm{A}), \mathrm{C} 1$ (1.355(4) $\AA$ ), and Pd1 (2.014(2) $\mathrm{A}$ ). $\mathrm{Ru} 1$ is $\pi$-coordinated to the C3-C4 bond and $\sigma$-coordinated to O1. Ru2 is $\pi$-coordinated to the C3-C4

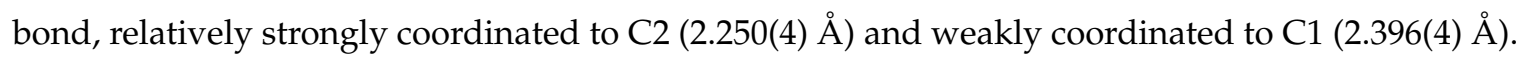

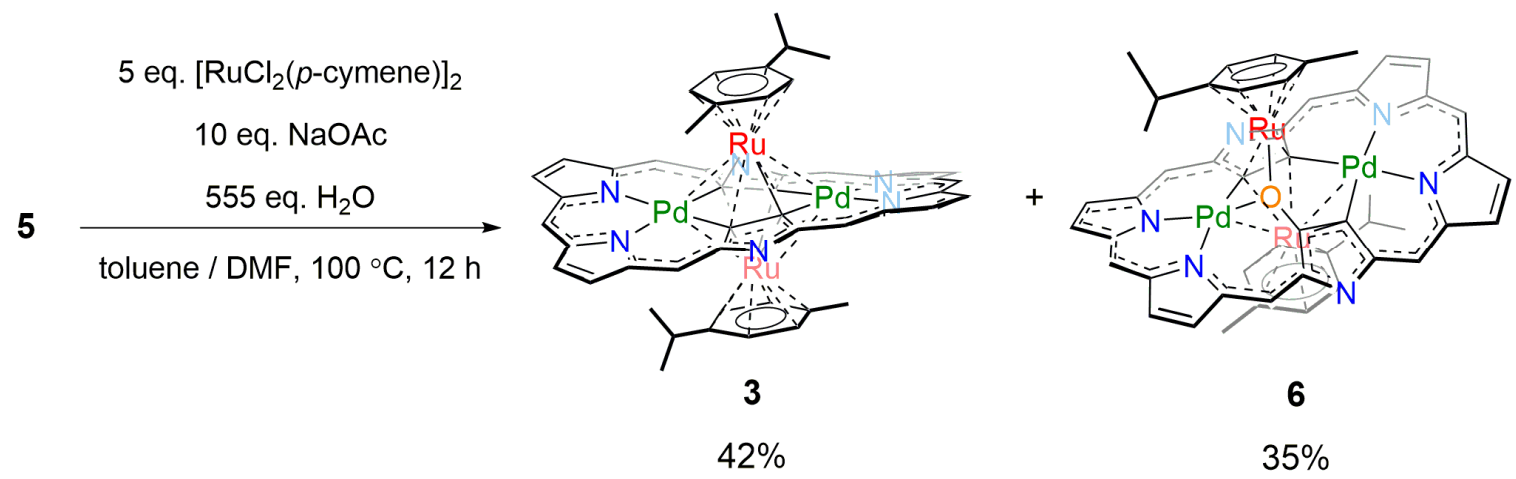

Scheme 2. Synthesis of 6. meso-Pentafluorophenyl groups are omitted for clarity.

(a)

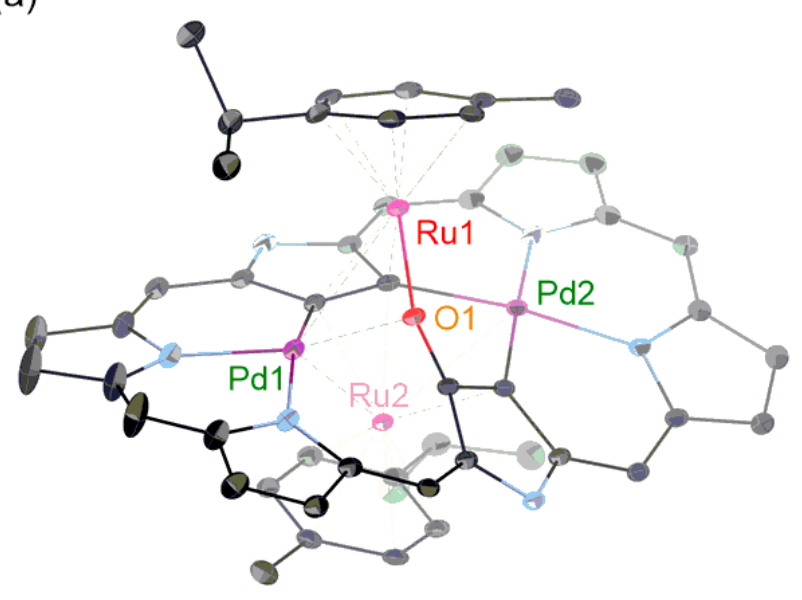

(b)

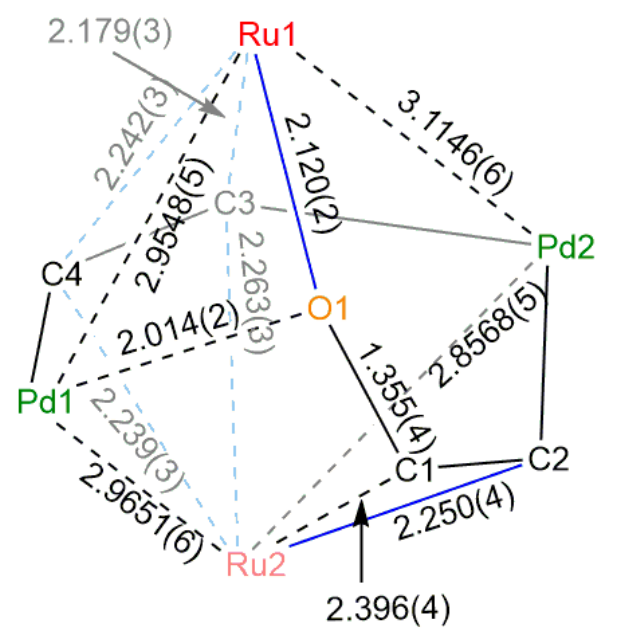

Figure 5. (a) X-Ray crystal structure of 6 . The thermal ellipsoids are $25 \%$ probability. Solvent molecules, pentafluorophenyl groups, and hydrogen atoms are omitted for clarity. (b) Detailed bond lengths of 6 . Bond lengths are shown in $\AA$.

On the basis of experimental results, 6 displays aromatic characters as follows: (i) The ${ }^{1} \mathrm{H}-\mathrm{NMR}$ spectrum of 6 shows eight doublet signals due to the outer $\beta$-protons in the range of $\delta=8.34-7.88 \mathrm{ppm}$ and upfield-shifted four doublets peak due to the aryl-protons of the $p$-cymene in the range of $\delta=3.09$ - 2.18 ppm; (ii) The nucleus-independent-chemical-shift (NICS) calculations also indicated negative values in several points inside the macrocycle of 6 (Figure S18); (iii) The absorption spectrum of 6 shows two Soret-like bands at 484 and $635 \mathrm{~nm}$ and one Q-like band at 879 nm (Figure 6). The lowest-energy band is relatively strong and red-shifted compared with that of 3. Virtually no solvent effects were observed for the absorption spectra of 6 (Figure S6). 


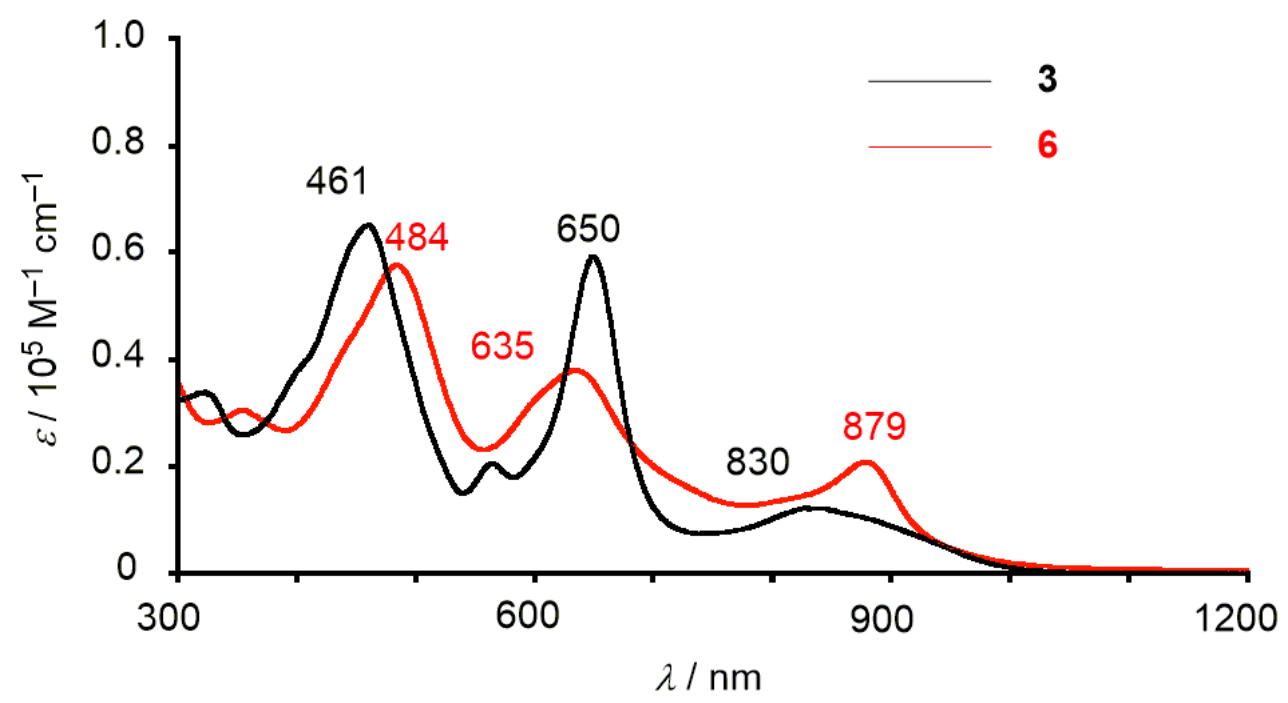

Figure 6. Absorption spectra of 3 (black) and 6 (red) in $\mathrm{CH}_{2} \mathrm{Cl}_{2}$.

In order to understand the real electronic states, we assumed several resonance contributors in 3, 4, and $\mathbf{6}$ as shown in Scheme 3. For 4, two resonance contributors can be considered, both of which have $26 \pi$ conjugation circuits regardless of the involvement of anions. As is the case in freebase hexaphyrins [22,23] and hexaphyrin bis-Pd(II) complex [19], the aromaticity of hexaphyrin dianion species becomes stronger than that of the neutral species. In contrast, the tetraanion of the hexaphyrin core in 3 can be drawn with three resonance contributors, one of which has a $28 \pi$ antiaromatic circuit. In order to estimate the relative contributions, the harmonic oscillator stabilization energies (HOSE) [24] have been calculated based on the crystal structures. The estimated weights for the canonical structures 3A, 3B, and 3C are $0.342,0.334$ and 0.325 , respectively. The calculated electrostatic potential map of 3 displayed relatively electronegative positions being roughly consistent with these canonical structures (Figure S19). Therefore, it could be assumed that non-negligible antiaromatic contribution caused the outer $\beta$-protons of 3 slightly upfield-shifted in the ${ }^{1} \mathrm{H}$-NMR spectrum as compared with 4 , in which both of the $26 \pi$ resonance contributors are estimated to be almost equally contributed ( 0.481 and 0.519 for $4 \mathrm{~A}$ and $\mathbf{4 B}$, respectively). With regard to 6 , six resonance contributors are considered as shown in Scheme 3c. The estimated weights for the canonical structures $6 \mathrm{~A}$ to $6 \mathrm{~F}$ can be estimated to be 0.189 , $0.182,0.168,0.162,0.152$, and 0.147 , respectively. Similarly to the case of 3 , the resonance contributors with $26 \pi$ systems (6A and $6 B$ ) are more important than those with $28 \pi$ systems ( $6 \mathrm{E}$ and $6 \mathrm{~F}$ ).

The electrochemical properties of 4 and 6 were examined by cyclic voltammetry (Table 1). [26]Hexaphyrin bis-Pd ${ }^{\mathrm{II}}$ complex 5 showed a relatively large electrochemical HOMO-LUMO gap $(1.21 \mathrm{eV})$ as a typical feature of an aromatic hexaphyrin [25]. Four reversible waves at $0.81,0.56,-0.43$, and $-1.01 \mathrm{~V}$ versus a ferrocene/ferrocenium ion couple were observed for double-decker complex 4 in $\mathrm{CH}_{2} \mathrm{Cl}_{2}$. While the electrochemical HOMO-LUMO gap was also increased upon $\mathrm{Ru}^{\mathrm{II}}$ metalation from $5(1.21 \mathrm{eV})$ to $3(1.51 \mathrm{eV})$, the oxidation and reduction potentials of 4 were negatively and positively shifted, respectively, in comparison with those of 5 , thus giving rise to a smaller gap of $0.99 \mathrm{eV}$ in 4 . The oxidation and reduction potentials of 6 were slightly negatively and positively shifted, respectively, from those of 3, thus giving rise to a smaller gap of $1.25 \mathrm{eV}$. The order of the electrochemical HOMO-LUMO gaps is in accordance with the spectral red-shifts at their lowest-energy bands. In addition, DFT calculations indicated the HOMO-LUMO gaps to be 1.76, 1.40, and $1.62 \mathrm{eV}$, for 3 [8], 4, and 6, respectively (Figures S10 and S11). The tendency of calculated HOMO-LUMO energy gaps also reflect their $\pi$-metalation-dependent aromaticity modulations. 
(a)

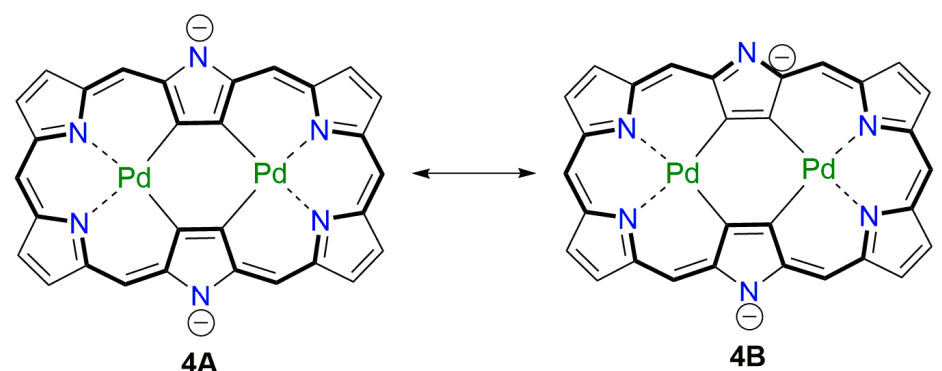

$26 \pi$ system

$26 \pi$ system

(b)

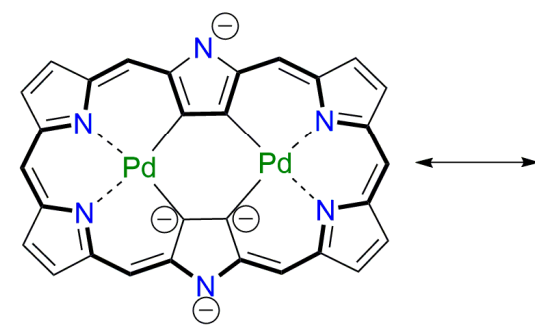

$3 A$

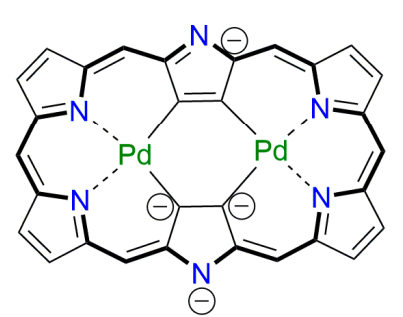

3B

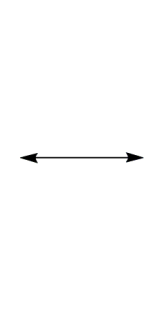

$26 \pi$ system

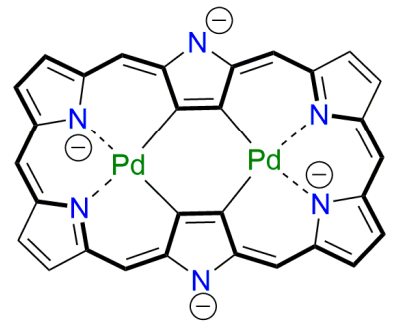

3C

(c)

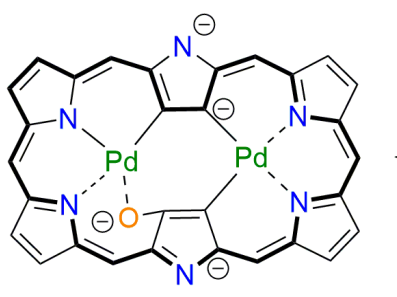

$6 A$

$26 \pi$ systems
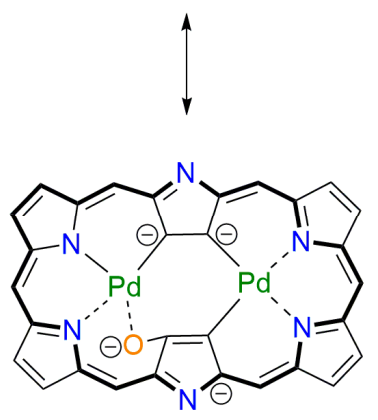

6D

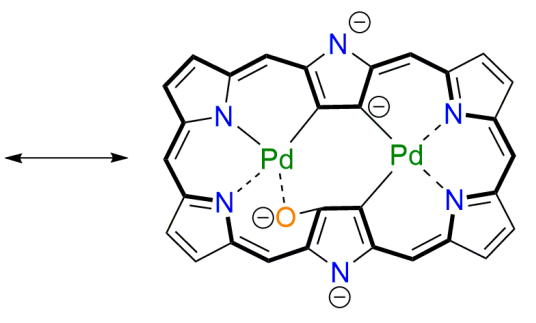

6B

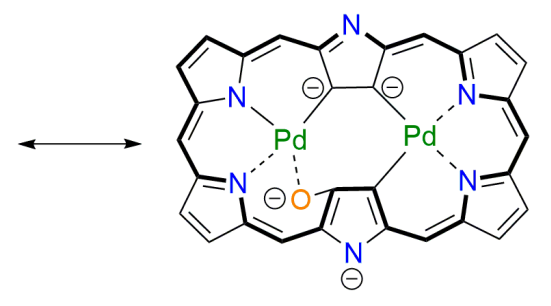

6C

$26 \pi$ system

$26 \pi$ system
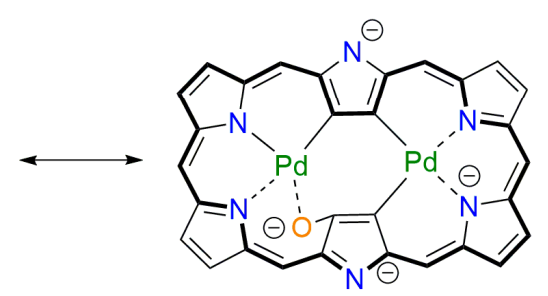

6E
$26 \pi$ systems
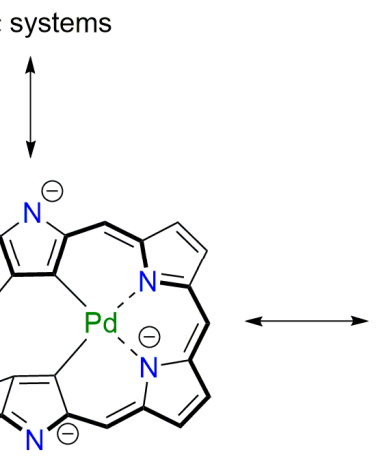

$28 \pi$ system

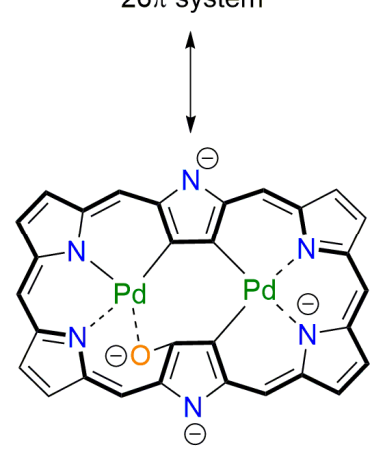

$6 \mathrm{~F}$

Scheme 3. (a) Plausible resonance contributors of hexaphyrin ligands of (a) 4, (b) 3 , and (c) 6 . Effective $\pi$-conjugated structures are indicated in bold lines. meso-Pentafluorophenyl groups are omitted for clarity. 
Table 1. Oxidation potentials $\left(E_{\mathrm{ox}}\right)$, reduction potentials $\left(E_{\mathrm{red}}\right) \mathrm{vs} \mathrm{Fc} / \mathrm{Fc}^{+}$in $\mathrm{V}$, and electrochemical HOMO-LUMO gaps $(\Delta E)$ for 3 to $6^{[\mathrm{a}]}$.

\begin{tabular}{cccccc}
\hline & $\boldsymbol{E}_{\text {ox.2 }}[\mathrm{V}]$ & $\boldsymbol{E}_{\text {ox.1 }}[\mathbf{V}]$ & $\boldsymbol{E}_{\text {red.1 }}[\mathrm{V}]$ & $\boldsymbol{E}_{\text {red.2 }}[\mathrm{V}]$ & $\boldsymbol{\Delta} \boldsymbol{E}[\mathrm{eV}]$ \\
\hline $\mathbf{3}[8]$ & 0.66 & 0.22 & -1.29 & & 1.51 \\
$\mathbf{4}$ & 0.81 & 0.56 & -0.43 & -1.01 & 0.99 \\
$\mathbf{5}[8]$ & & 0.71 & -0.50 & -0.93 & 1.21 \\
$\mathbf{6}$ & 0.56 & 0.17 & -1.08 & -1.62 & 1.25 \\
\hline
\end{tabular}

[a] Cyclic voltammograms were measured under the following conditions: solvent $\mathrm{CH}_{2} \mathrm{Cl}_{2}$, scan rate $0.05 \mathrm{~V} \mathrm{~s}^{-1}$, working electrode $\mathrm{Pt}$, counter electrode $\mathrm{Pt}$ wire, reference electrode $\mathrm{Ag} / \mathrm{AgNO} \mathrm{N}_{3}$, supporting electrolyte $n \mathrm{Bu}_{4} \mathrm{NPF}_{6}$.

\section{Materials and Methods}

The chemicals used for synthesis were of reagent grade quality unless otherwise mentioned. Dry toluene was obtained by distillation over $\mathrm{CaH}_{2}$. Dry DMF was purchased from Wako (FUJIFILM Wako Pure Chemical Corportaion, 1-2, Doshomachi 3-chome, Chuo-ku, Osaka, Japan). Silica gel column chromatography was performed on Wako gel C-300 and C-400 unless otherwise mentioned. ${ }^{1} \mathrm{H}(600.17 \mathrm{MHz})$ and ${ }^{19} \mathrm{~F}(564.73 \mathrm{MHz})$ NMR spectra were acquired on an ECA-600 spectrometer (JEOL Ltd., 3-1-2 Musashino, Akishima-shi, Tokyo, JAPAN) and chemical shifts were reported as the delta scale in ppm relative to $\mathrm{CHCl}_{3}$ as internal references for ${ }^{1} \mathrm{H}(\delta=7.26 \mathrm{ppm})$, and hexafluorobenzene as an external reference for ${ }^{19} \mathrm{~F}(\delta=-162.9 \mathrm{ppm})$. Coupling constants $(J)$ are given in Hz. High-resolution atmospheric-pressure-chemical-ionization time-of-flight (HR-APCI-TOF) mass spectra were recorded on a micrOTOF LC instrument BRUKER Daltonics (Bruker Corporation, 3-9, Moriya-cho, Kanagawa-ku, Yokohama-shi, Kanagawa, Japan). UV/Vis/NIR absorption spectra were recorded on a UV-3600PC spectrometer (Shimadzu Corporation, 1, Nishinokyo Kuwabara-cho, Nakagyo-ku, Kyoto, Japan). Redox potentials were measured by cyclic voltammetry on model ALS 612E electrochemical analyzer (BAS Inc., 1-28-12, Mukaijima, Sumida-ku, Tokyo, Japan). X-Ray single crystal diffraction analyses were performed on an XtaLAB P200 apparatus (Rigaku Corporation, 3-9-12, Matsubara-cho, Akishima-shi, Tokyo, Japan) at $-180{ }^{\circ} \mathrm{C}$ using a two-dimensional PILATUS $100 \mathrm{~K} / \mathrm{R}$ detector with CuK $\alpha$ radiation $(\lambda=1.54187 \AA)$. The structures were solved by direct method SHELEXT-2014/5, and refined by SHELEXL-2014/7 programs [26-28].

\subsection{Oxidation of $\mathbf{3}$ into [26]Hexaphyrin Bis-Pd(II)-Mono-Ru(II) Complex 4}

A solution containing $3(11.6 \mathrm{mg}, 5.5 \mu \mathrm{mol})$ and tris(4-bromophenyl)ammoniumyl hexachloroantimonate ( $202.1 \mathrm{mg}, 248 \mu \mathrm{mol}, 45 \mathrm{eq}$.) in $\mathrm{CH}_{2} \mathrm{Cl}_{2}$ was stirred for $10 \mathrm{~min}$. The resulting mixture was passed through $\gamma$-alumina column and the solvent was removed under reduced pressure. The residue was separated by silica-gel column chromatography $\left(\mathrm{C} 300, \mathrm{CH}_{2} \mathrm{Cl}_{2}: n\right.$-hexane $=1: 2$ to 1:0) and a red fraction was collected. Recrystallization from $\mathrm{CH}_{2} \mathrm{Cl}_{2} / n$-hexane afforded 4 as dark red solids (3.6 mg, $2.2 \mu \mathrm{mol}, 41 \%$ ).

\subsection{Direct Synthesis of [26]Hexaphyrin Bis-Pd(II)-Mono-Ru(II) Complex 4}

A solution containing [26]hexaphyrin bis-Pd(II) complex 5 (162.2 $\mathrm{mg}, 97.2 \mu \mathrm{mol})$, $\left[\mathrm{RuCl}_{2} \text { (p-cymene) }\right]_{2}(304.9 \mathrm{mg}, 498 \mu \mathrm{mol}, 5 \mathrm{eq}$.), and sodium acetate $(84.0 \mathrm{mg}, 1.00 \mathrm{mmol}, 10 \mathrm{eq}$.) in dry toluene $(40 \mathrm{~mL})$ and dry DMF $(10 \mathrm{~mL})$ was stirred for $13 \mathrm{~h}$ at room temperature. The solution was added to water and extracted with $\mathrm{CH}_{2} \mathrm{Cl}_{2}$. The combined organic layer was dried over $\mathrm{Na}_{2} \mathrm{SO}_{4}$ and the solvent was removed in vacuo. The crude mixture was separated by silica-gel column chromatography $\left(\mathrm{CH}_{2} \mathrm{Cl}_{2}: n\right.$-hexane $=1: 2$ to 1:0), and a green fraction and a red fraction were collected. Removal of solvent of green fraction afforded 3 as green solids ( $10.9 \mathrm{mg}, 5.1 \mu \mathrm{mol}, 5 \%)$. Recrystallization of red fraction from $\mathrm{CH}_{2} \mathrm{Cl}_{2} / n$-hexane afforded 4 as dark red solids (130.4 mg, $\left.68.6 \mu \mathrm{mol}, 71 \%\right)$. Compound data of 3 were described [8]. Compound data of 4 are as follows: ${ }^{1} \mathrm{H}-\mathrm{NMR}\left(\mathrm{CDCl}_{3}, 298 \mathrm{~K}\right)$ $\delta[\mathrm{ppm}]=9.45(\mathrm{~d}, 4 \mathrm{H}, J=4.6 \mathrm{~Hz}, \beta-\mathrm{H}), 9.24(\mathrm{~d}, 4 \mathrm{H}, J=4.6 \mathrm{~Hz}, \beta-\mathrm{H}), 0.16(\mathrm{~d}, 2 \mathrm{H}, J=5.5 \mathrm{~Hz}, \mathrm{Ar}-\mathrm{H})$, $0.13(\mathrm{~d}, 2 \mathrm{H}, J=5.5 \mathrm{~Hz}, \mathrm{Ar}-\mathrm{H}),-1.77\left(\mathrm{~d}, 6 \mathrm{H}, J=6.9 \mathrm{~Hz}, \mathrm{CH}\left(\mathrm{CH}_{3}\right)_{2}\right),-2.01(\mathrm{~s}, 3 \mathrm{H}, \mathrm{Me})$, and -2.38 
$\left(\mathrm{m}, 1 \mathrm{H}, \mathrm{CH}\left(\mathrm{CH}_{3}\right)_{2}\right) .{ }^{19} \mathrm{~F}-\mathrm{NMR}\left(\mathrm{CDCl}_{3}, 298 \mathrm{~K}\right) \delta[\mathrm{ppm}]=-133.97(\mathrm{~d}, 4 \mathrm{~F}, J=21.7 \mathrm{~Hz}, o-\mathrm{F}),-135.90$ $(\mathrm{d}, 2 \mathrm{~F}, J=30.3 \mathrm{~Hz}, o-\mathrm{F}),-136.67(\mathrm{~d}, 2 \mathrm{~F}, J=17.3 \mathrm{~Hz}, o-\mathrm{F}),-139.65(\mathrm{~d}, 4 \mathrm{~F}, J=17.3 \mathrm{~Hz}, o-\mathrm{F}),-151.07(\mathrm{t}$, $2 \mathrm{~F}, J=21.7 \mathrm{~Hz}, p-\mathrm{F}),-153.98(\mathrm{t}, 4 \mathrm{~F}, J=21.7 \mathrm{~Hz}, p-\mathrm{F}),-160.97(\mathrm{t}, 4 \mathrm{~F}, J=21.7 \mathrm{~Hz}, m-\mathrm{F}),-161.63(\mathrm{t}, 8 \mathrm{~F}$, $J=19.5 \mathrm{~Hz}, m-\mathrm{F}),-162.59(\mathrm{t}, 5 \mathrm{~F}, J=19.5 \mathrm{~Hz}, m-\mathrm{F})$, and $-163.33(\mathrm{t}, 4 \mathrm{~F}, J=21.7 \mathrm{~Hz}, m-\mathrm{F})$. UV/Vis/NIR $\left(\mathrm{CH}_{2} \mathrm{Cl}_{2}\right): \lambda_{\max }[\mathrm{nm}]\left(\varepsilon\left[\mathrm{M}^{-1} \mathrm{~cm}^{-1}\right]\right)=345$ (29000), 410 (26000), 487 (45000), 548 (43000), 677 (51000), 812 (17000), and 1179 (1600).

HR APCI-TOF-MS (negative): $m / z$ calcd. for $\mathrm{C}_{76} \mathrm{H}_{22} \mathrm{~F}_{30} \mathrm{~N}_{6}{ }^{106} \mathrm{Pd}_{2}{ }^{102} \mathrm{Ru}: 1901.8589,[M]^{-}$; found: 1901.8531.

\section{3. [26]Hexaphyrin Bis-Pd(II)-Bis-Ru(II)-Oxygen Inserted Complex 6}

A solution containing $5(17.2 \mathrm{mg}, 10.3 \mu \mathrm{mol}),\left[\mathrm{RuCl}_{2}(p \text {-cymene })\right]_{2}(32.0 \mathrm{mg}, 52.3 \mu \mathrm{mol}, 5$ eq. $)$, and sodium acetate $(8.3 \mathrm{mg}, 98.8 \mathrm{mmol}, 9$ eq. $)$ in toluene $(4 \mathrm{~mL}), \mathrm{DMF}(1 \mathrm{~mL})$ and $\mathrm{H}_{2} \mathrm{O}(0.1 \mathrm{~mL})$ was stirred for $12 \mathrm{~h}$ at $100{ }^{\circ} \mathrm{C}$. The solution was added to water and extracted with $\mathrm{CH}_{2} \mathrm{Cl}_{2}$. The combined organic layer was dried over $\mathrm{Na}_{2} \mathrm{SO}_{4}$ and the solvent was removed in vacuo. The crude mixture was separated by silica-gel column chromatography $\left(\mathrm{C}-400, \mathrm{CH}_{2} \mathrm{Cl}_{2}\right.$ :n-hexane $\left.=1: 2\right)$, and a green fraction and a dark green fraction were collected. Removal of solvent of the green fraction afforded 3 as green solids $(9.2 \mathrm{mg}, 4.3 \mu \mathrm{mol}, 42 \%)$. Removal of solvent of the dark green fraction afforded 6 as green solids (7.8 mg, 3.6 $\mu \mathrm{mol}, 35 \%) .{ }^{1} \mathrm{H}-\mathrm{NMR}\left(\mathrm{CDCl}_{3}, 298 \mathrm{~K}\right) \delta[\mathrm{ppm}]=8.34(\mathrm{~d}, 1 \mathrm{H}, J=5.5 \mathrm{~Hz}, \beta-\mathrm{H}), 8.24(\mathrm{~d}, 1 \mathrm{H}$, $J=4.1 \mathrm{~Hz}, \beta-\mathrm{H}), 8.20(\mathrm{~d}, 1 \mathrm{H}, J=4.6 \mathrm{~Hz}, \beta-\mathrm{H}), 8.17(\mathrm{~d}, 1 \mathrm{H}, J=4.6 \mathrm{~Hz}, \beta-\mathrm{H}), 8.13(\mathrm{~d}, 1 \mathrm{H}, J=4.6 \mathrm{~Hz}, \beta-\mathrm{H})$, $8.08(\mathrm{~d}, 1 \mathrm{H}, J=5.5 \mathrm{~Hz}, \beta-\mathrm{H}), 8.01(\mathrm{~d}, 1 \mathrm{H}, J=4.6 \mathrm{~Hz}, \beta-\mathrm{H}), 7.88(\mathrm{~d}, 1 \mathrm{H}, J=5.0 \mathrm{~Hz}, \beta-\mathrm{H}), 3.09(\mathrm{~d}, 2 \mathrm{H}$, $J=5.5 \mathrm{~Hz}, \mathrm{Ar}-\mathrm{H}), 2.79(\mathrm{~d}, 2 \mathrm{H}, J=5.5 \mathrm{~Hz}, \mathrm{Ar}-\mathrm{H}), 2.46(\mathrm{~d}, 2 \mathrm{H}, J=5.5 \mathrm{~Hz}, \mathrm{Ar}-\mathrm{H}), 2.18(\mathrm{~d}, 2 \mathrm{H}, J=5.5 \mathrm{~Hz}$, $\mathrm{Ar}-\mathrm{H}), 1.25$ (s, 6H, CH(CH$\left.)_{2}\right), 0.86\left(\mathrm{~m}, 1 \mathrm{H}, \mathrm{CH}\left(\mathrm{CH}_{3}\right)_{2}\right),-0.01\left(\mathrm{~m}, 6 \mathrm{H}, \mathrm{CH}\left(\mathrm{CH}_{3}\right)_{2}\right),-0.29(\mathrm{~s}, 3 \mathrm{H}, \mathrm{Me})$, $-0.59(\mathrm{~s}, 3 \mathrm{H}, \mathrm{Me})$, and $-1.87\left(\mathrm{~m}, 1 \mathrm{H}, \mathrm{CH}\left(\mathrm{CH}_{3}\right)_{2}\right) .{ }^{19} \mathrm{~F}-\mathrm{NMR}\left(\mathrm{CDCl}_{3}, 298 \mathrm{~K}\right) \delta[\mathrm{ppm}]=-135.03(\mathrm{~s}, 1 \mathrm{~F}$, $o-\mathrm{F}),-135.34(\mathrm{~s}, 1 \mathrm{~F}, o-\mathrm{F}),-136.11(\mathrm{~d}, 1 \mathrm{~F}, J=21.7 \mathrm{~Hz}, o-\mathrm{F}),-136.90(\mathrm{~s}, 1 \mathrm{~F}, o-\mathrm{F}),-137.28(\mathrm{~d}, 2 \mathrm{~F}, J=17.3 \mathrm{~Hz}$, $o-\mathrm{F}),-137.80(\mathrm{~d}, 2 \mathrm{~F}, J=26.0 \mathrm{~Hz}, o-\mathrm{F}),-138.46(\mathrm{~d}, 2 \mathrm{~F}, J=17.3 \mathrm{~Hz}, o-\mathrm{F}),-139.33(\mathrm{~d}, 1 \mathrm{~F}, J=21.7 \mathrm{~Hz}, o-\mathrm{F})$, $-139.66(\mathrm{~d}, 1 \mathrm{~F}, J=26.0 \mathrm{~Hz}, o-\mathrm{F}),-152.58(\mathrm{t}, 1 \mathrm{~F}, J=21.7 \mathrm{~Hz}, p-\mathrm{F}),-152.78(\mathrm{t}, 1 \mathrm{~F}, J=19.5 \mathrm{~Hz}, p-\mathrm{F}),-154.49$ $(\mathrm{t}, 1 \mathrm{~F}, J=19.5 \mathrm{~Hz}, p-\mathrm{F}),-155.09(\mathrm{t}, 1 \mathrm{~F}, J=21.7 \mathrm{~Hz}, p-\mathrm{F}),-155.52(\mathrm{~m}, 2 \mathrm{~F}, p-\mathrm{F}),-161.76(\mathrm{~m}, 4 \mathrm{~F}, m-\mathrm{F})$, $-162.85(\mathrm{t}, 1 \mathrm{~F}, J=19.5 \mathrm{~Hz}, m-\mathrm{F}),-163.18(\mathrm{t}, 1 \mathrm{~F}, J=19.5 \mathrm{~Hz}, m-\mathrm{F}),-163.59(\mathrm{t}, 1 \mathrm{~F}, J=19.5 \mathrm{~Hz}, m-\mathrm{F})$, and $-164.00(\mathrm{~m}, 5 \mathrm{~F}, m-\mathrm{F})$. UV/Vis/NIR $\left(\mathrm{CH}_{2} \mathrm{Cl}_{2}\right): \lambda_{\max }[\mathrm{nm}]\left(\varepsilon\left[\mathrm{M}^{-1} \mathrm{~cm}^{-1}\right]\right)=353(31000), 484(58000)$, 635 (38000), and 879 (21000). HR APCI-TOF-MS (negative): $m / z$ calcd. for $\mathrm{C}_{86} \mathrm{H}_{36} \mathrm{~F}_{30} \mathrm{~N}_{6} \mathrm{O}^{106} \mathrm{Pd}_{2}{ }^{102} \mathrm{Ru}_{2}$ : 2153.8682, $[M]^{-}$; found: 2153.8690.

\subsection{Synthesis of [26]Hexaphyrin Bis-Pd(II)-Bis-Ru(II)-Oxygen Inserted Complex 6 under Argon Atmosphere}

A solution containing $5(16.7 \mathrm{mg}, 10.0 \mu \mathrm{mol}),\left[\mathrm{RuCl}_{2}(p \text {-cymene })\right]_{2}(30.9 \mathrm{mg}, 50.5 \mu \mathrm{mol}, 5$ eq. $)$, and sodium acetate $(9.2 \mathrm{mg}, 109 \mu \mathrm{mol}, 10$ eq.) in dry toluene $(4 \mathrm{~mL})$ and dry DMF (1 mL) was stirred for $9 \mathrm{~h}$ at $100{ }^{\circ} \mathrm{C}$ under argon atmosphere. After the reaction mixture was cooled to room temperature, the solution was added to water and extracted with $\mathrm{CH}_{2} \mathrm{Cl}_{2}$. The combined organic layer was dried over $\mathrm{Na}_{2} \mathrm{SO}_{4}$ and the solvent was removed in vacuo. The crude mixture was separated by silica-gel column chromatography $\left(\mathrm{C}-400, \mathrm{CH}_{2} \mathrm{Cl}_{2}\right.$ :n-hexane $\left.=1: 2\right)$, and the green fraction was collected. Removal of solvent afforded 3 as green solids $(14.6 \mathrm{mg}, 6.8 \mu \mathrm{mol}, 68 \%)$. Only a trace amount of 6 was detected.

\section{Conclusions}

In summary, one of the ruthenoarene units of the triple-decker complex 3 was detached by oxidation with TBAH, affording the new double-decker complex 4 . While the aromaticity of 3 was weaker than that of parent [26] hexaphyrin 5, that of 4 was slightly enhanced. This conflicting result was explained by the resonance contributors of hexaphyrin di- and tetraanion ligands. Given the fact that $\pi$-complexation often disturbs the macrocyclic ring current, 4 is a quite rare example whose aromaticity was enhanced by $\pi$-metal coordination. For oxygen-inserted triple-decker complex 6, one of the two rutheniums was $\pi$-coordinated to a $C=C$ double bond on one side and was $\sigma$-coordinated 
to oxygen on the other side. Again, this complex exhibited distinct aromatic characters, suggesting the active involvement of $26 \pi$ aromatic resonance contributors. Further studies on novel $\pi$-complexes of expanded porphyrins are actively ongoing.

Supplementary Materials: The following are available online. Figures S1 and S2: ${ }^{1} \mathrm{H}-$ and ${ }^{19} \mathrm{~F}-\mathrm{NMR}$ spectra, Figure S3: Observed and simulated HR-APCI-TOF-MS, Figures S4 to S6: UV/Vis absorption spectra, Figure S7: Cyclic voltammograms, Figures S8 and S9: X-Ray structures, Figures S10 and S11: Kohn-Sham orbital diagrams, Figures S12 to S14: Calculated absorption spectra, Figures S15 and S16. ACID isosurfaces, Figures S17 and S18: NICS(0) values, Figures S19 to S21: Three-dimensional molecular electrostatic potential, Tables S1 and S2: Bond lengths (X-ray and DFT calculation) and bond order (DFT), Tables S3 and S4: Harmonic oscillator stabilization energies and estimated weights, Schemes S1 and S2: Plausible resonance contributors. References [29-31] are cited in the supplementary materials.

Author Contributions: All authors contributed to the writing of the manuscript. A.N. conducted all the experiments. All authors have read and agreed to the published version of the manuscript.

Funding: This work was supported by JSPS KAKENHI grant numbers JP18H03910 and JP20K05463. A.N. appreciates a JSPS Research Fellowship for Young Scientists: 20J20954.

Acknowledgments: The authors thank H. Yorimitsu at Kyoto University for HR-MS measurements.

Conflicts of Interest: The authors declare no conflict of interest.

\section{References}

1. Sessler, J.L.; Seidel, D. Synthetic Expanded Porphyrin Chemistry. Angew. Chem. Int. Ed. 2003, 42, 5134-5175. [CrossRef] [PubMed]

2. Chandrashekar, T.K.; Venkatraman, S. Core-Modified Expanded Porphyrins: New Generation Organic Materials. Acc. Chem. Res. 2003, 36, 676-691. [CrossRef] [PubMed]

3. Shimizu, S.; Osuka, A. Metalation Chemistry of meso-Aryl-Substituted Expanded Porphyrins. Eur. J. Inorg. Chem. 2006, 1319-1335. [CrossRef]

4. Stępień, M.; Sprutta, N.; Latos-Grażyński, L. Figure Eights, Möbius Bands, and More: Conformation and Aromaticity of Porphyrinoids. Angew. Chem. Int. Ed. 2011, 50, 4288-4340. [CrossRef] [PubMed]

5. Saito, S.; Osuka, A. Expanded Porphyrins: Intriguing Structures, Electronic Properties, and Reactivities. Angew. Chem. Int. Ed. 2011, 50, 4342-4373. [CrossRef] [PubMed]

6. Tanaka, T.; Osuka, A. Chemistry of meso-Aryl-Substituted Expanded Porphyrins: Aromaticity and Molecular Twist. Chem. Rev. 2017, 117, 2584-2640. [CrossRef]

7. Szyszko, B.; Białek, M.J.; Pacholska-Dudziak, E.; Latos-Grażyński, L. Flexible Porphyrinoids. Chem. Rev. 2017, 117, 2839-2909. [CrossRef]

8. Nakai, A.; Ishida, S.-i.; Soya, T.; Osuka, A. $\pi$-Ruthenium Complexes of Hexaphyrins(1.1.1.1.1.1): A Triple-Decker Complex Bearing Two Ruthenoarene Units. Angew. Chem. Int. Ed. 2019, 58, 8197-8200. [CrossRef]

9. Cuesta, L.; Sessler, J.L. $\pi$-Metal complexes of tetrapyrrolic systems. A novel coordination mode in "porphyrin-like" chemistry. Chem. Soc. Rev. 2009, 38, 2716-2729. [CrossRef]

10. Dailey, K.K.; Yap, G.P.A.; Rheingold, A.L.; Rauchfuss, T.B. Metalloporphyrins as Ligands: Synthesis and Characterization of $\left[\left(\eta^{6}-\text { cymene)-Ru }\left\{\eta^{5}-\mathrm{Ni}(\mathrm{OEP})\right\}\right]^{2+}\right.$. Angew. Chem. Int. Ed. Engl. 1996, 35, 1833-1835. [CrossRef]

11. Dailey, K.K.; Rauchfuss, T.B. $\pi$-Complexes of metalloporphyrins as model intermediates in hydrodemetallation (HDM) catalysis. Polyhedron 1997, 16, 3129-3138. [CrossRef]

12. Cuesta, L.; Karnas, E.; Lynch, V.M.; Sessler, J.L.; Kajonkijya, W.; Zhu, W.; Zhang, M.; Ou, Z.; Kadish, K.M.; Ohkubo, K.; et al. (Pentamethylcyclopentadienyl)ruthenium $\pi$-Complexes of Metalloporphyrins: Platforms with Novel Photo- and Electrochemical Properties. Chem. Eur. J. 2008, 14, 10206-10210. [CrossRef] [PubMed]

13. Cuesta, L.; Karnas, E.; Lynch, V.M.; Chen, P.; Shen, J.; Kadish, K.M.; Ohkubo, K.; Fukuzumi, S.; Sessler, J.L. Metalloporphycenes: Synthesis and Characterization of (Pentamethylcyclopentadienyl)ruthenium Sitting-Atop and $\pi$-Complexes. J. Am. Chem. Soc. 2009, 131, 13538-13547. [CrossRef] [PubMed]

14. Vargas-Zúñigaa, G.I.; Roznyatovskiy, V.V.; Nepomnyaschii, A.; Lynch, V.M.; Sessler, J.L. $\pi$-Metal complexes of $i$-propyldinaphthoporphycene. J. Porphyrins Phthalocyanines 2012, 16, 479-487. [CrossRef] 
15. Caballero, E.; Fernández-Ariza, J.; Lynch, V.M.; Romero-Nieto, C.; Rodríguez-Morgade, M.S.; Sessler, J.L.; Guldi, D.M.; Torres, T. Cyclopentadienylruthenium $\pi$ Complexes of Subphthalocyanines: A “Drop-Pin” Approach To Modifying the Electronic Features of Aromatic Macrocycles. Angew. Chem. Int. Ed. 2012, 51, 11337-11342. [CrossRef]

16. Caballero, E.; Romero-Nieto, C.; Strau $\beta$, V.; Rodríguez-Morgade, M.S.; Guldi, D.M.; Sessler, J.L.; Torres, T. Ruthenoarenes versus Phenol Derivatives as Axial Linkers for Subporphyrazine Dimers and Trimers. Chem. Eur. J. 2014, 20, 6518-6525. [CrossRef] [PubMed]

17. Perekalin, D.S.; Kudinov, A.P. Cyclopentadienyl ruthenium complexes with naphthalene and other polycyclic aromatic ligands. Coord. Chem. Rev. 2014, 276, 153-173. [CrossRef]

18. Kadish, K.M.; Caemelbecke, E.V.; Royal, G. Electrochemistry of Metalloporphyrins in Nonaqueous Media in The Porphyrin Handbook; Kadish, K.M., Smith, K.M., Guilard, R., Eds.; Academic Press: Boston, MA, USA, 2000; Volume 8, Chapter 55; pp. 1-260.

19. Yoneda, T.; Osuka, A. Synthesis of a [26]Hexaphyrin Bis-Pd ${ }^{\mathrm{II}}$ Complex with a Characteristic Aromatic Circuit. Chem. Eur. J. 2013, 19, 7314-7318. [CrossRef]

20. Batsanov, S.S. Van der Waals Radii of Elements. Inorg. Mater. 2001, 37, 871-885. [CrossRef]

21. DFT Calculations Were Performed at the B3LYP/6-31G(d) (C, H, O, N, F) + LANL2DZ (Pd, Ru) Level, Using the Gaussian 16 Program; Gaussian Revision A.03; Gaussian, Inc.: Wallingford, CT, USA, 2016.

22. Suzuki, M.; Osuka, A. Reversible caterpillar-motion like isomerization in a $N, N^{\prime}$-dimethyl hexaphyrin(1.1.1.1.1.1) induced by two-electron oxidation or reduction. Chem. Commun. 2005, 3685-3687. [CrossRef]

23. Cha, W.-Y.; Lim, J.M.; Yoon, M.-C.; Sung, Y.M.; Lee, B.S.; Katsumata, S.; Suzuki, M.; Mori, H.; Ikawa, H.; Furuta, H.; et al. Deprotonation-Induced Aromaticity Enhancement and New Conjugated Networks in meso-Hexakis(pentafluorophenyl)[26]hexaphyrin. Chem. Eur. J. 2012, 18, 15838-15844. [CrossRef] [PubMed]

24. Krygowski, T.M.; Szatylowicz, H.; Stasyuk, O.A.; Dominikowska, J.; Palusiak, M. Aromaticity from the Viewpoint of Molecular Geometry: Application to Planar Systems. Chem. Rev. 2014, 114, 6383-6422. [CrossRef]

25. Tanaka, T.; Aratani, N.; Lim, J.M.; Kim, K.S.; Kim, D.; Osuka, A. Porphyrin-hexaphyrin hybrid tapes. Chem. Sci. 2011, 2, 1414-1418. [CrossRef]

26. Sheldrick, G.M. SHELXT-Integrated space-group and crystal-structure determination. Acta Cryst. 2015, A71, 3-8. [CrossRef] [PubMed]

27. Sheldrick, G.M.; Schneider, T.R. SHELXL: High-resolution refinement. Methods Enzymol. 1997, 277, 319-343. [PubMed]

28. Sheldrick, G.M. Crystal structure refinement with SHELXL. Acta Cryst. 2015, C71, 3-8.

29. Herges, R.; Geuenich, D. Delocalization of Electrons in Molecules. J. Phys. Chem. A 2001, 105, 3214-3220. [CrossRef]

30. Geuenich, D.; Hess, K.; Köhler, F.; Herges, R. Anisotropy of the Induced Current Density (ACID), a General Method To Quantify and Visualize Electronic Delocalization. Chem. Rev. 2005, 105, 3758-3772. [CrossRef]

31. Glendening, E.D.; Reed, A.E.; Carpenter, J.E.; Weinhold, F. NBO Version 3.1; Gaussian Inc.: Pittsburgh, PA, USA, 2003.

Sample Availability: Samples of the compounds 4 and $\mathbf{6}$ are available from the authors. 